\title{
A Numerical Simulation of the Effect of Buffer Layer Band Gap on the Performances of $n c-S i$ : H Based Solar Cells
}

\author{
H. Touati1, B. Amiri2,, , A.C. Sebbak², A. Benameur², H. Aït-kaci² \\ ${ }^{1}$ Material Technology Department, Faculty of Physics, Oran University of Sciences and Technology Mohamed \\ Boudiaf USTO-MB, BP1505 Oran, Algeria \\ ${ }^{2}$ Laboratory of Plasma Physics, Conductor Materials and their Applications, Faculty of Physics, Oran University of \\ Sciences and Technology Mohamed Boudiaf USTO-MB, BP1505 Oran, Algeria
}

(Received 03 February 2016; revised manuscript received 10 June 2016; published online 21 June 2016)

\begin{abstract}
This paper describes an investigation, by using numerical simulation, into the impacts of $i$-nc-Si : $\mathrm{H}$ buffer layer band gap on the photovoltaic parameters of $n-i-p$ hydrogenated nanocrystalline silicon $(n c-\mathrm{Si}: \mathrm{H})$ solar cells. The output external cell parameters, like, the short-circuit current $\left(J_{S C}\right)$, the open circuit voltage $\left(V_{O C}\right)$, the fill factor $(F F)$ and efficiency $\left(E_{f f}\right)$ are simulated by varying the mobility band gap $(E g)$ of i-nc-Si : H buffer layer. Also, the band diagram of $n c-\mathrm{Si}: \mathrm{H} n-i-p$ solar cell, the electric field and the traped hole density at $i / p$ interface, and the external quantum efficiency, with different values of buffer layer band gap where optimized. The simulation result shows that in valence band and for both interfaces, the band offsets $\Delta E_{V 1}$ at p-nc-Si : H (window layer) / i-nc-Si : H (buffer layer) and $\Delta E_{V 2}$ at i-nc-Si : H (buffer layer) / $i-n c-\mathrm{Si}: \mathrm{H}$ (absorber layer) can be affected by varying $E_{g}$. It is obtained that the values efficiency are $10.89 \%$ and $11.33 \%$ when the value of i-nc-Si : $\mathrm{H}$ buffer layer band gap are $1.4 \mathrm{eV}$ and $1.55 \mathrm{eV}$, respectively. However, the $i$-nc-Si : $\mathrm{H}$ buffer layer band gap of $1.55 \mathrm{eV}$ was optimized for obtaining a better efficiency for $n$-i- $p$ solar cell based on hydrogenated nanocrystalline silicon.
\end{abstract}

Keywords: Nanocrystalline silicon, Buffer layer, Band gap, Simulation.

DOI: $10.21272 /$ jnep.8(2).02008

PACS numbers: 73.40.Lq, 78.20.Bh

\section{INTRODUCTION}

Solar cells based on thin-film silicon (TF-Si) have received much attention due to the raw materials and the potential for large-area manufacturing. Especially, for the past few years, hydrogenated amorphous silicon ( $a$-Si : $\mathrm{H})$ solar cells, have received wide industrial and scientific attention due to their low temperature deposition and low production cost $[1,2]$. However, $a$-Si : H cells have poor stability against the light. Changes in the light and dark conductivity of $a-\mathrm{Si}: \mathrm{H}$ material due to light soaking was reported for the first time by Staebler and Woronski in 1977 and the metastability of $a$-Si : H, since then called the Staebler-Woronski effect [3]. As a result of this effect, the performance of $a$-Si : $\mathrm{H}$ solar cells degrades following prolonged illumination [4]. Such issues have lead to think to make certain modification in the exiting amorphous material. In 1968, an interesting material called microcrystalline silicon was developed. Microcrystalline hydrogenated silicon ( $\mu c-\mathrm{Si}: \mathrm{H})$, also called as nanocrystalline silicon $(n c-\mathrm{Si}: \mathrm{H})$ in the literature, has been widely used in various electronic devices and solar cells [5]. The solar cell performance is influenced by structural, optical, and electronic properties of the material. The material consistes of nanometer-sized crystallites clustered to form large grains with sizes of submicrometer to micrometers, embded in amorphous silicon matrix [6].

For solar cell applications, not only the electronic properties of the materials but also the stability of electronic properties under prolonged illumination are important. The nc-Si : H material has received great attention by many research groups because of its better optical absorption than crystalline silicon. Also, unlike amorphous silicon ( $a$ - $\mathrm{Si}: \mathrm{H})$, it has stable transport properties that are not influenced by light induced degradation [7]. Hydrogenated nanocrystalline silicon $(n c-\mathrm{Si}: \mathrm{H})$ is one promising material for silicon-based thin film solar cells, particularly as the bottom cell material in tandem solar cells $[8,9]$. Therefore, the optimization of single-junction nc-Si : $\mathrm{H}$ solar cells is needed to obtain tandem cells with higher efficiency. In the optimization of single-junction nc-Si : $\mathrm{H}$ solar cell, research on the $p / i$ interface is important since $p / i$ interface has a significant impact on the solar cell performance when the $i$-layer quality is very good $[10,11]$.

In this study, we report the results of a systematic study of the effects of the hydrogenated nanocrystalline ( $i$-nc-Si : H) buffer layer, incorporaed at $p / i$ interface, on $n c-\mathrm{Si}$ : $\mathrm{H}$ solar cells performance by using device simulations. The obtained results show that cell performance is closely affected by band gap variations of this buffer layer.

\section{STRUCTURE OF THE SIMULATED SOLAR CELL AND SIMULATION MODEL}

The structure of the simulated hydrogenated nannocrystalline silicon $(n c-\mathrm{Si}: \mathrm{H})$ solar cell was contain a $15 \mathrm{~nm}$ thick front $p$-doped layer of $n c$ $\mathrm{Si}: \mathrm{H}$, a $10 \mathrm{~nm}$ thick back $n$-doped layer of $n c-\mathrm{Si}: \mathrm{H}$, and an intrinsic $n c$-Si:H with a thickness of $1800 \mathrm{~nm}$ was used as absorber layer. An intrinsic $n c$ $\mathrm{Si}$ : $\mathrm{H}$ buffer layer with a thickness of $5 \mathrm{~nm}$, has been incorporated between the $p$-layer and the absorber $i$ layer. For the front contact, we have used an ITO layer as a TCO (Transparent Conducting Oxide) deposited on the $p$-side. The structure was consid-

\footnotetext{
*a_belfar@hotmail.com
} 
ered deposited on a metal (stainless steel) substrate which functions as a back contact (Fig. 1).

Sun light

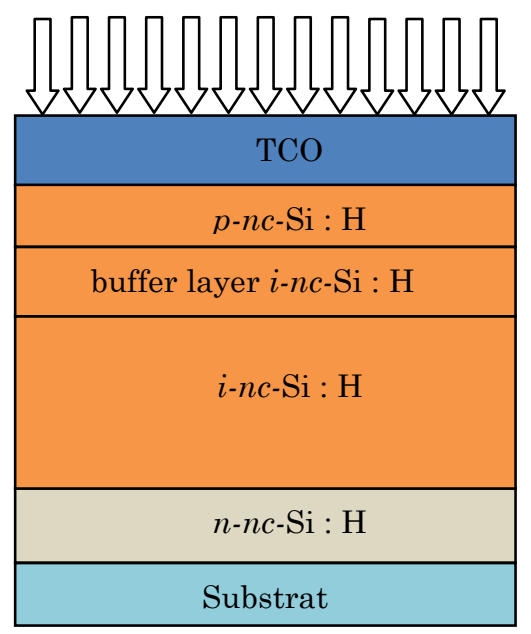

Fig. 1 - Shematic view of $n c-\mathrm{Si}: \mathrm{H}$ simulated structure

The simulation study was carried out using AMPS1D (One Dimensional Analysis of Microelectronic and Photonic structures) simulator. AMPS-1D program simulates and analyses the properties of heterojunction solar cells through solving the onedimensional Poisson equation and the electron and hole continuity equations, based on Shockley-Read-Hall recombination statistics, by using the method of finite differences and the Newton-Raphson technique $[12,13]$. We studied how the band gap of $i$-nc-Si : H buffer-layer affect the performance of $n-i-p$ solar cell based on hydrogenated nanocrystalline silicon.

A model of the continuous density of states (DOS) was applied, in this simulation. For the density of localized states in the mobility gap of different layers, it has been assumed that there were both donor-like states and acceptor-like states. Both of these donor and acceptor-like states consisted of tail states and midgap defect states (dangling bonds). The tail states were approximated by exponential distribution. Whereas the midgap defects were modeled using tow Gaussian distributions and are usually given as follows:

$$
\begin{aligned}
& g_{D G}(E)=\left(\frac{N_{D G}}{\sqrt{2 \pi} \sigma_{D G}}\right) \exp \left(-\frac{\left(E-E_{D G}\right)^{2}}{2 \sigma_{D G}{ }^{2}}\right) \\
& g_{A G}(E)=\left(\frac{N_{A G}}{\sqrt{2 \pi} \sigma_{A G}}\right) \exp \left(-\frac{\left(E-E_{A G}\right)^{2}}{2 \sigma_{A G}{ }^{2}}\right)
\end{aligned}
$$

In these equations $N_{D G}$ and $N_{A G}$ are the total number of states in the Gaussian $\left(\mathrm{cm}^{-3}\right), E_{D G}$ and $E_{A G}$ are the energy position (in eV) of the peak of the Gaussians, and $\sigma_{D G}$ and $\sigma_{A G}$ are the standard energy deviations (also in eV). AMPS-1D assumes that midgap states can be modeled using a donor level to represent the $D^{+} / D^{0}$ dangling-bond configuration and an acceptor level to represent the $D^{0} / D^{-}$configuration $[12,13]$.

The simulation requires input parameters such as surface recombination velocities, barrier heights, power density of the radiation and characteristics of the layers forming the structure to simulate. The main parameters used in the calculation are shown in Table 1.
In this calculation, we assumed that the front contact barrier height $\varphi_{b 0}$ (TCO/p-layer) was $1.40 \mathrm{eV}$ and the back contact barrier height $\varphi_{b L}$ ( $n$ layer/metal) is chosen equal to $0.21 \mathrm{eV}$. The surface recombination speeds of electrons and holes were both $1 \times 10^{7} \mathrm{~cm} / \mathrm{s}$. As a source of illumination, an AM 1.5 solar radiation with a power density of $100 \mathrm{~mW} / \mathrm{cm}^{2}$ was used. The light absorption coefficient, for the different layers was already incorporated in the AMPS-1D program. We also assumed that the back contact has a reflection (RB) coefficient of 0.60 . However, the reflection of light at the front face (RF) was set at 0.2. In this simulation $p$-layer and $n$-layer were assumed to be highly doped, which is the same as experimental data, thus the acceptor and donor concentration were assumed to be high $3 \times 19^{19} \mathrm{~cm}^{-3}$ and $1 \times 10^{19} \mathrm{~cm}^{-3}$, respectively.

\section{RESULTS AND DISCUSSION}

In order to reduce the effect of band offset at the $p$-nc-Si : $\mathrm{H}$ window layer/i-nc-Si : $\mathrm{H}$ layer heterojunction interface, we have introduced a thin $(5 \mathrm{~nm}) i$-nc$\mathrm{Si}$ : $\mathrm{H}$ buffer-layer at this interface. During the optimization of $i$-nc-Si : H buffer-layer bandgap the values of $p$-nc-Si : $\mathrm{H}$ window layer, $i$-nc-Si : $\mathrm{H}$ absorber layer and $n$-nc-Si : $\mathrm{H}$ layer band gaps where kept as $1.65 \mathrm{eV}$, $1.50 \mathrm{eV}$ and $1.60 \mathrm{eV}$, respectively. The thicknesses of $p$-layer, absorber layer and $\mathrm{n}$ layer were kept as $15 \mathrm{~nm}$, $1800 \mathrm{~nm}$ and $10 \mathrm{~nm}$, respectively. For this, we varying the band gap of $i$ - $n c-\mathrm{Si}: \mathrm{H}$ buffer layer from $1.40 \mathrm{eV}$ to $1.60 \mathrm{eV}$. Fig. 2a-d shows the variations of $J_{S C}, V_{O C}, F F$ and efficiency with variations of $i-n c-\mathrm{Si}: \mathrm{H}$ buffer-layer band gap. From Fig. 2a, we can see that $J_{S C}$ is slowly affected by $i$-nc-Si : H buffer layer band gap variations. However, $J_{S C}$ increase from $20.92 \mathrm{~mA} / \mathrm{cm}^{2}$ to $21.10 \mathrm{~mA} / \mathrm{cm}^{2}$ with increasing the $i-n c-\mathrm{Si}: \mathrm{H}$ buffer layer band gap from $1.40 \mathrm{eV}$ to $1.55 \mathrm{eV}$. Beyond $1.55 \mathrm{eV}$, value of $J_{S C}$ was found to decrease very slowly.

The variations of $V O C$ with $i$-nc-Si : H buffer-layer band gap where presented in Fig. 2b. From this figure, we can see, when the buffer layer band gap value range between $1.40 \mathrm{eV}$ and $1.55 \mathrm{eV}$ the $V_{O C}$ increased from $744 \mathrm{mV}$ to $762 \mathrm{mV}$, there has been an improvement of $18 \mathrm{mV}$. However, when $i$-nc-Si : $\mathrm{H}$ buffer layer band gap increased from $1.55 \mathrm{eV}$ to $1.60 \mathrm{eV}$ the values of $V_{O C}$ were maintained constant. The variations of $F F$ with $i$-nc-Si : H buffer-layer band gap where presented in Fig. 2(c). Initially, the value of FF increase from $70 \%$ to $70.30 \%$ when the band gap value increase from 1.40 $\mathrm{eV}$ to $1.46 \mathrm{eV}$.

The simulated results of efficiency where showed in Fig. 2(d). The efficiency was found to gradually increase from $10.89 \%$ to $11.33 \%$ with increasing $i$-nc-Si : H buffer layer band gap from $1.40 \mathrm{eV}$ to $1.55 \mathrm{eV}$. However, beyond $1.55 \mathrm{eV}$ the value of efficiency remains constant. Hence, $i$-nc-Si : H buffer-layer band gap of $1.55 \mathrm{eV}$ was optimized for obtaining high efficiency for $n$-i-p nanocrystalline silicon solar cell.

In order to understand, in depth, the solar cell's output parameters variations with increasing the $i$-nc$\mathrm{Si}$ : $\mathrm{H}$ buffer layer band gap, we have shown the band diagrams of $n-i-p$ solar cell at thermodynamic equilibrium in Fig. 3(a)-(d). The band offset $\Delta E_{C}$ causes a barrier in the conduction band (Fig. 2a) which acts as a mirror 

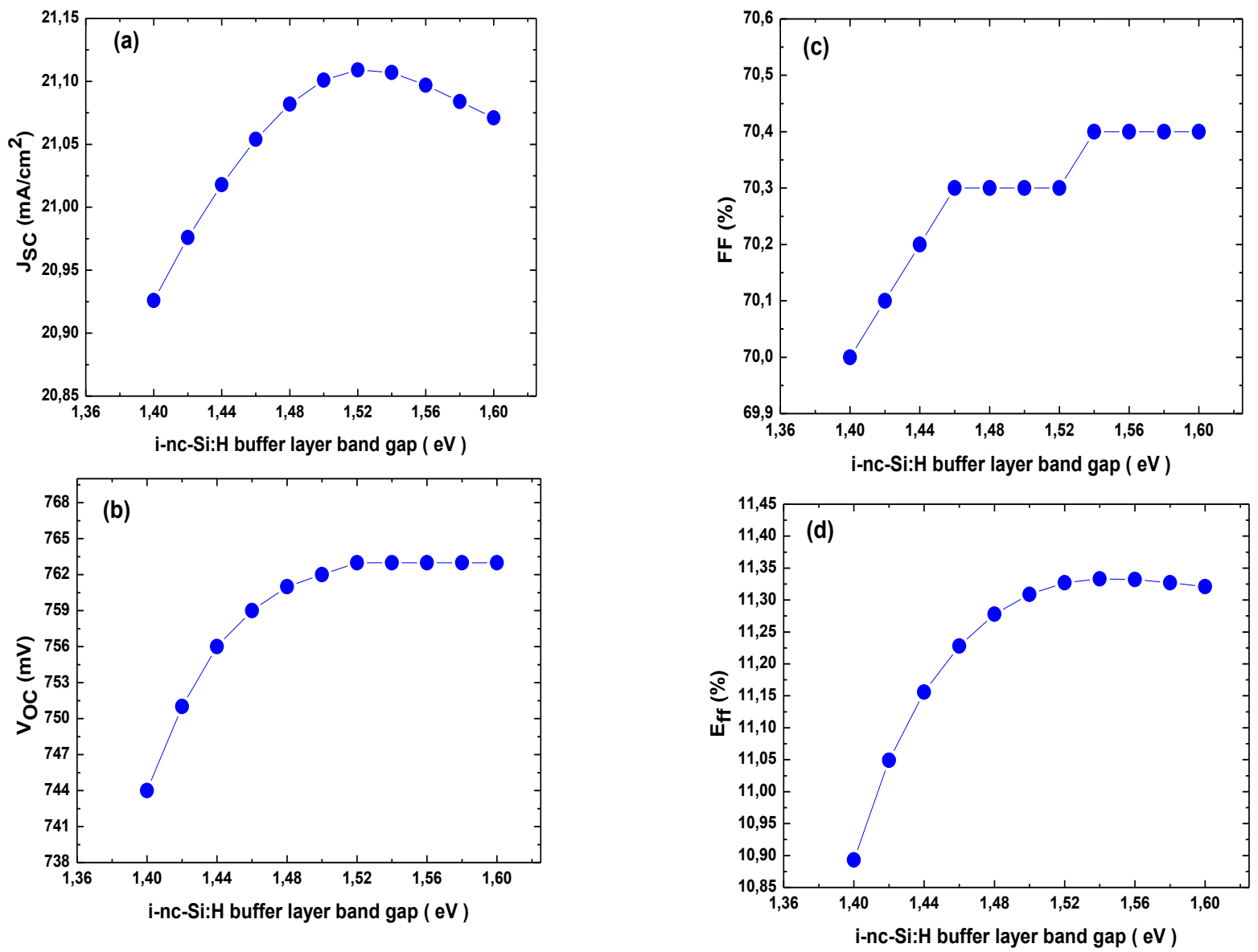

Fig. 2 - Variations of (a) $J_{S C}$, (b) $V_{O C}$, (c) $F F$ and (d) efficiency with $i$-nc-Si : H buffer layer band gap for $n$-i-p solar cell

Table 1 - Material parameters used for AMPS-1D simulations at room temperature

\begin{tabular}{|c|c|c|c|c|}
\hline Parameters & $p-n c-\mathrm{Si}: \mathrm{H}$ & tampon $i-n c-\mathrm{Si}: \mathrm{H}$ & $i-n c-\mathrm{Si}: \mathrm{H}$ & $n-n c-\mathrm{Si}: \mathrm{H}$ \\
\hline$\varepsilon_{r}$ & 11,9 & 11,9 & 11,9 & 11,9 \\
\hline$L(\mathrm{~nm})$ & 15 & 5 & 1800 & 10 \\
\hline$x(\mathrm{eV})$ & 3,9 & 4,00 & 4,00 & 4,00 \\
\hline$E_{g}(\mathrm{eV})$ & 1.65 & variable & 1.5 & 1,60 \\
\hline$N_{C}\left(\mathrm{~cm}^{-3}\right)$ & $1 \times 10^{21}$ & $2 \times 10^{20}$ & $2 \times 10^{20}$ & $2 \times 10^{20}$ \\
\hline$N_{V}\left(\mathrm{~cm}^{-3}\right)$ & $1 \times 10^{21}$ & $2 \times 10^{20}$ & $2 \times 10^{20}$ & $2 \times 10^{20}$ \\
\hline$\mu_{e-}\left(\mathrm{cm}^{2} \mathrm{~V}^{-1} \mathrm{~s}^{-1}\right)$ & 100 & 32 & 32 & 10 \\
\hline$\mu_{h+}\left(\mathrm{cm}^{2} \mathrm{~V}^{-1} \mathrm{~s}^{-1}\right)$ & 25 & 8 & 8 & 4 \\
\hline$N_{A}\left(\mathrm{~cm}^{-3}\right)$ & $3 \times 10^{19}$ & 0 & 0 & 0 \\
\hline$N_{D}\left(\mathrm{~cm}^{-3}\right)$ & 0 & 0 & 0 & $1 \times 10^{19}$ \\
\hline $\mathrm{G}_{\mathrm{DO}} / \mathrm{G}_{\mathrm{AO}}\left(\mathrm{cm}^{-3} \mathrm{eV}^{-1}\right)$ & $1 \times 10^{22}$ & $4 \times 10^{21}$ & $2 \times 10^{21}$ & $4 \times 10^{21}$ \\
\hline$E_{D} / E_{A}(\mathrm{eV})$ & $0,02 / 0,01$ & $0,02 / 0,01$ & $0,02 / 0,01$ & $0,05 / 0,03$ \\
\hline$\sigma_{\text {de }}\left(\mathrm{cm}^{2}\right)$ (Tails) & $4 \times 10^{-16}$ & $1 \times 10^{-15}$ & $1 \times 10^{-15}$ & $1 \times 10^{-15}$ \\
\hline$\sigma_{\mathrm{dh}}\left(\mathrm{cm}^{2}\right)$ (Tails) & $2 \times 10^{-17}$ & $1 \times 10^{-17}$ & $1 \times 10^{-16}$ & $1 \times 10^{-17}$ \\
\hline$\sigma_{\mathrm{ae}}\left(\mathrm{cm}^{2}\right)$ (Tails) & $2 \times 10^{-17}$ & $1 \times 10^{-17}$ & $1 \times 10^{-16}$ & $1 \times 10^{-17}$ \\
\hline$\sigma_{\mathrm{ah}}\left(\mathrm{cm}^{2}\right)$ (Tails) & $4 \times 10^{-16}$ & $1 \times 10^{-15}$ & $1 \times 10^{-15}$ & $1 \times 10^{-15}$ \\
\hline$N_{D G}\left(\mathrm{~cm}^{-3}\right)$ & $1 \times 10^{17}$ & $2 \times 10^{15}$ & $2 \times 10^{15}$ & $5 \times 10^{18}$ \\
\hline
\end{tabular}




\begin{tabular}{|lllll|}
\hline$N_{A G}\left(\mathrm{~cm}^{-3}\right)$ & $1 \times 10^{17}$ & $2 \times 10^{15}$ & $2 \times 10^{15}$ & $5 \times 10^{18}$ \\
$E_{D G} / E_{A G}(\mathrm{eV})$ & $1,25 / 1,15$ & $1,13 / 0,15$ & $1,08 / 0,98$ & $1,05 / 0,96$ \\
$\sigma_{\mathrm{de}}\left(\mathrm{cm}^{2}\right)$ (Gauss.) & $1 \times 10^{-14}$ & $1 \times 10^{-14}$ & $1 \times 10^{-15}$ & $1 \times 10^{-15}$ \\
$\sigma_{\mathrm{dh}}\left(\mathrm{cm}^{2}\right)$ (Gauss.) & $1 \times 10^{-16}$ & $1 \times 10^{-16}$ & $1 \times 10^{-16}$ & $1 \times 10^{-16}$ \\
$\sigma_{\mathrm{ae}}\left(\mathrm{cm}^{2}\right)$ (Gauss.) & $1 \times 10^{-16}$ & $1 \times 10^{-16}$ & $1 \times 10^{-16}$ & $1 \times 10^{-16}$ \\
$\sigma_{\text {ah }}\left(\mathrm{cm}^{2}\right)$ (Gauss.) & $1 \times 10^{-14}$ & $1 \times 10^{-14}$ & $1 \times 10^{-15}$ & $1 \times 10^{-15}$ \\
\hline
\end{tabular}

The abbreviations used in this table are the following: $\mathcal{E}_{r}$ : relative dielectric permittivity, $L$ : film thickness, $x$ : electron affinity, $E_{g}$ : energy band gap, $\mu_{e}, \mu_{h}$ : mobility of electrons and holes, $N_{D}, N_{A}$ : doping donor and acceptor, $N_{C}, N_{V}$ : effective densities of states in the conduction and valence bands, $N_{D G}, N_{A G}$ : Gaussian densities for donor and acceptor states, $G_{D O}$, $G_{A O}$ : exponential prefactors of donor-like or acceptor-like tail states, $E_{D}, E_{A}$ : characteristic energy of the donor-like/acceptor-like tail states, $E_{D G} / E_{A G}$ : donor and acceptor Gaussian peak energy position. $\sigma_{\mathrm{de}}, \sigma_{\mathrm{dh}}$ :Capture cross-section for donor states, $e, h$ and $\sigma_{\mathrm{ae},} \sigma_{\mathrm{ah}}$ : Capture crosssection for acceptor states $e, h$.
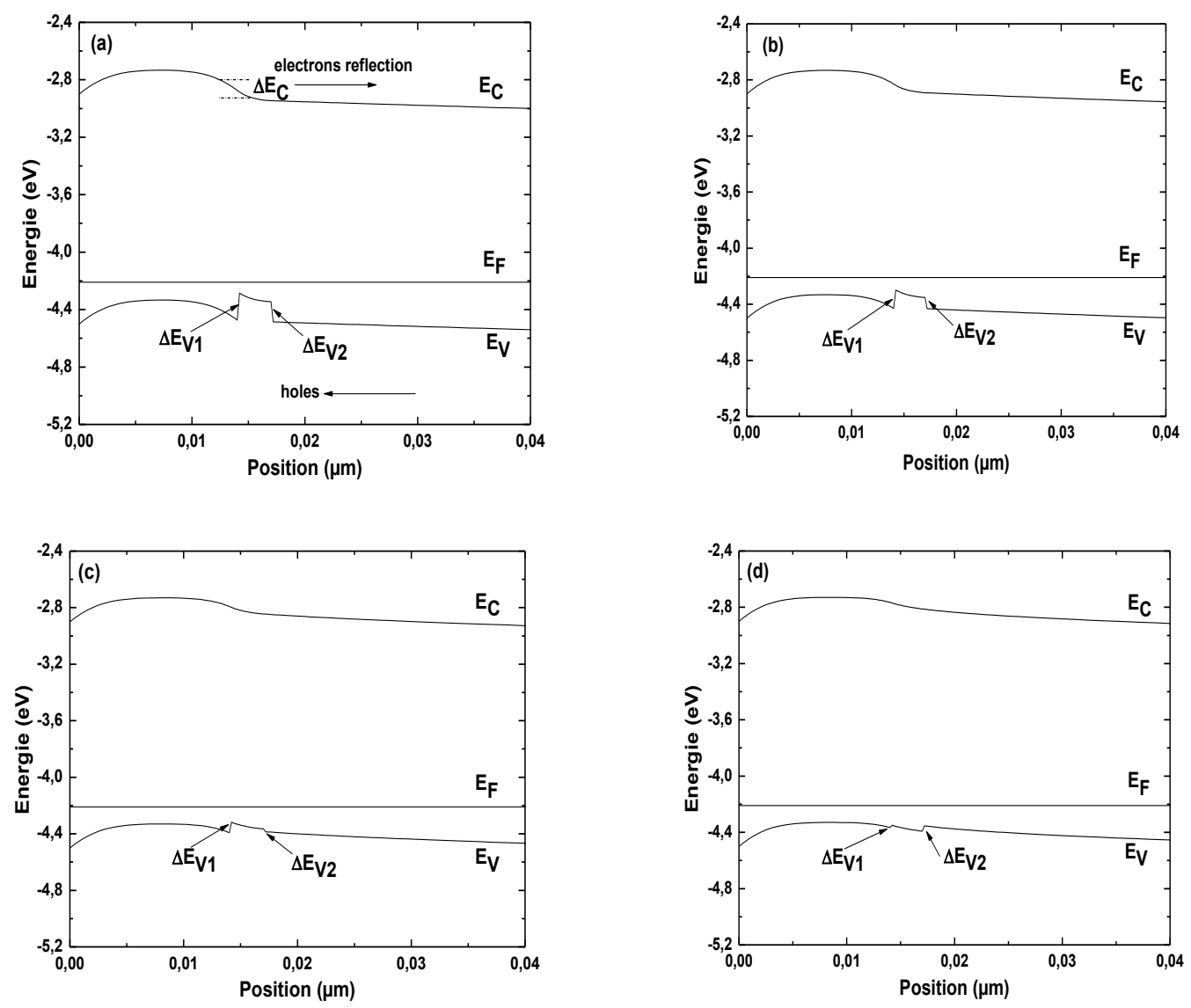

Fig. 3 - Energy band diagram of simulated $n-i-p$ solar cells based on $n c-\mathrm{Si}: \mathrm{H}$ when $i$-nc-Si : $\mathrm{H}$ buffer-layer band gap is (a) $E_{g}=1.4 \mathrm{eV}$, (b) $E_{g}=1.46 \mathrm{eV}$, (c) $E_{g}=1.55 \mathrm{eV}$, (d) $E_{g}=1.60 \mathrm{eV}$

for electrons and this is benificial to improve the solar cell performance. For the band offset $\Delta E_{V}$, and when inc-Si:H buffer layer band gap range from $1.40 \mathrm{eV}$ to $1.46 \mathrm{eV}$ the band offsets in valence band, for both interfaces are high, $\Delta E_{V 1}$ at $p$ - $n c$-Si : $\mathrm{H}$ (window layer) / $i$ - $n c$ $\mathrm{Si}: \mathrm{H}$ (buffer layer) and $\Delta E_{V 2}$ at $i$-nc-Si : $\mathrm{H}$ (buffer layer) / $i$-nc-Si : H (absorber layer), which explains the low values of the cell's output parameteres at the beginning in Fig. 2(a)-(b). To better interpret these results, we have calculated and presented in Fig. 4 the electric field at $p / i$ inteface for two different values of $i$-nc-Si : H buffer layer band gap. The electric field intensity is equal to $5.5 \times 10^{5} \mathrm{~V} / \mathrm{cm}$ when the gap of the buffer layer is $1.40 \mathrm{eV}$. However, when the value of the gap increas- es to $1.55 \mathrm{eV}$ the intensity of the electric field decreases and becomes $2 \times 10^{5} \mathrm{~V} / \mathrm{cm}$. So, this result explain clearly why the quantity of photoge-nerated holes traped at $i / p$ interface presented in Fig. 5 is higher and equal to $2 \times 10^{19} \mathrm{~cm}^{-1}$, when the value of band gap buffer layer is $1.4 \mathrm{eV}$ (Fig. 5). But, with a $i-n c-\mathrm{Si}: \mathrm{H}$ buffer layer which has a band gap equal to $1.55 \mathrm{eV}$, the traped hole density decrease drastically and a value of $5 \times 10^{18} \mathrm{~cm}^{-}$ 3 is obtained (Fig. 5). Therfore, the presence of the $i$-nc$\mathrm{Si}$ : $\mathrm{H}$ buffer layer leads to smaller values of valence band offsets. However, when the junction field separates the photogenerated $e-h$ pairs, electrons have to move towards $n$-side through conduction band and holes have to move easily towards $p$-side through va- 
lence band [14]. In addition, the incorporation of the $i$ $n c-\mathrm{Si}: \mathrm{H}$ buffer layer, with a value band gap equal to $1.55 \mathrm{eV}$, between the $p-n c-\mathrm{Si}: \mathrm{H}$ window layer and the $i$-nc-Si: $\mathrm{H}$ absorber layer reduce the recombination rate, near the $p$-window/ $i$-absorber interface [15]. Also, an improvement of the external quantum efficiency can be obviously observed in our calculated curves presented in Fig. 6. It is known, the short circuit current $J_{S C}$ is given by [16]:

$$
J_{S C}=q \int_{(\lambda)} \Phi(\lambda)\{1-R(\lambda)\} Q E(\lambda) d \lambda
$$

Where $Q E(\lambda)$ is the quantum efficiency; $R(\lambda)$ is the reflection coefficient frome the top surface; $\Phi(\lambda)$ is the photon flux incident on the solar cell at wavelength $\lambda$. The integration is carried out over all the range of wavelenght $\lambda$ of light absorbed by the structure. We can see from Fig. 6 , that the presence of the $i$-nc-Si : H buffer layer, with a value band gap equal to $1.55 \mathrm{eV}$ can improve the quantum efficiency in short range of spectrum wavelength from $350 \mathrm{~nm}$ to $600 \mathrm{~nm}$. According to the Eq. (3), this will lead to an improvement of short circuit current $J_{S C}$ presented in Fig. 2(a). This result has been obtained by several authors [15, 17, 18].

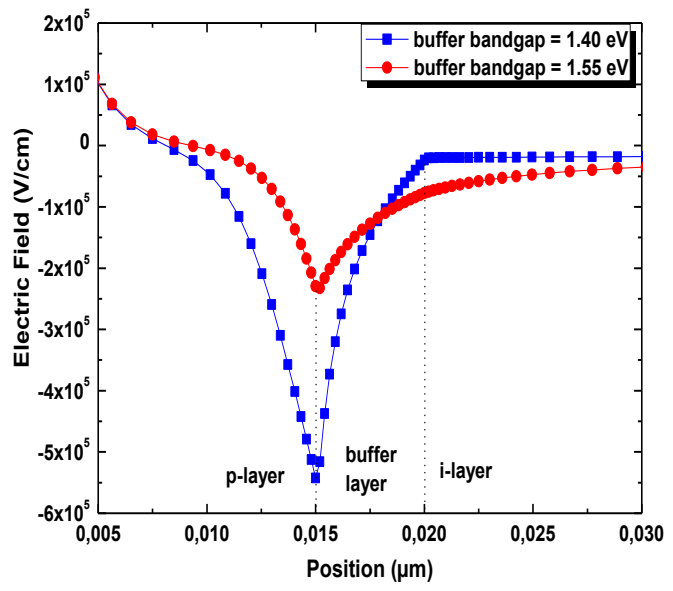

Fig. 4 - Electric field at $i / p$ interface under illumination for two different values of $i$-nc-Si : H buffer layer band gap

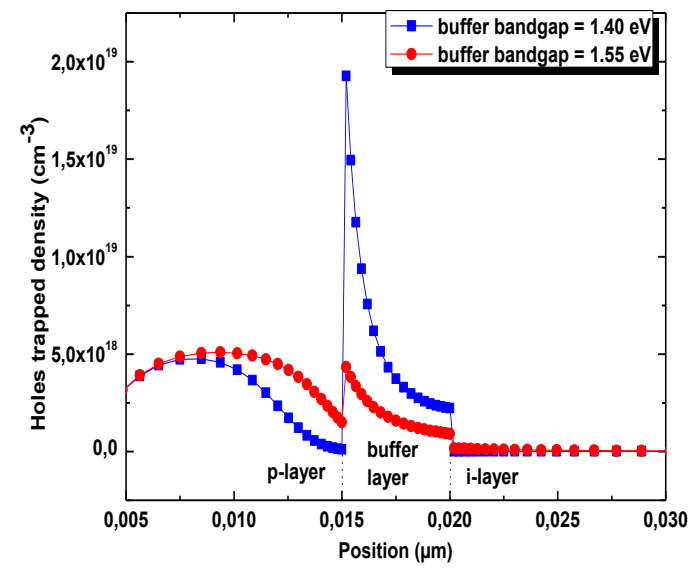

Fig. 5 - Trapped hole densities at $i / p$ interface for two different values of $i$-nc-Si : $\mathrm{H}$ buffer layer band gap
Our calulated values of efficiency where presented in Fig. 2(d). The value of efficiency increased from $10.89 \%$ to $11.33 \%$, when the band gap value increase from $1.40 \mathrm{eV}$ to $1.55 \mathrm{eV}$. However, beyond $1.56 \mathrm{eV}$ the value of efficiency decreased very slowly. This is can be attributed to the gradually increases of band offset $\Delta E_{V 2}$ at $i$ - $n c$-Si : H (buffer layer) / $i$-nc-Si : H (absorber layer) interface presented in Fig. 3(d), which causes a barrier for photogenerated holes that are trying to move towards the front contact through valence band. Thus, the $i$-nc-Si : H buffer layer band gap of $1.55 \mathrm{eV}$ was optimized for obtaining a better efficieny for $n-i-p$ solar cell based on hydrogenated nanocrystalline silicon.

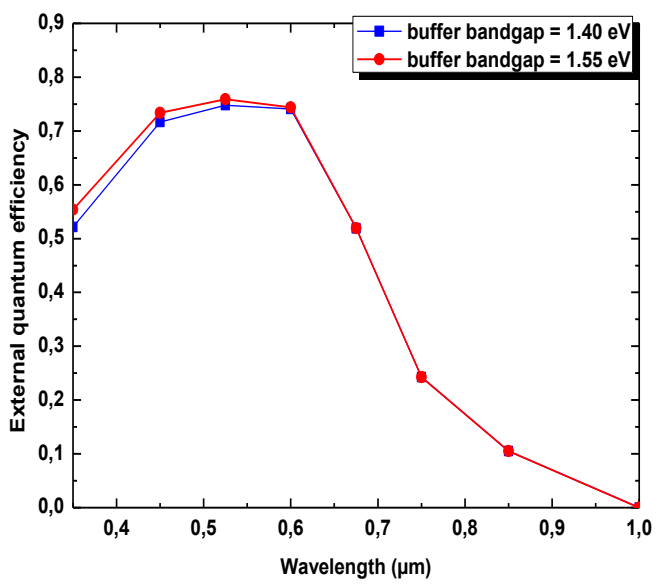

Fig. 6 - External quantum efficiency for $n-i-p$ hydrogenated nanocrystalline silicon solar cell for two different values of $i$-nc-Si : H buffer layer band gap

\section{CONCLUSION}

In this work, by using AMPS-1D software code, we carried out a simulation study to optimize the band gap of $i$-nc-Si : H buffer layer and its effects on the output performances of $n-i-p$ hydogenated nanocrystalline silicon solar cells. For this, we have varied the values of buffer layer in the range of $1.4 \mathrm{eV}-1.60 \mathrm{eV}$. From the obtained simulations results, we oserved that the presence of $i-n c-\mathrm{Si}: \mathrm{H}$ buffer layer, at $i / p$ interface, can reduce the electric field intensity from $5.5 \times 10^{5} \mathrm{~V} / \mathrm{cm}$ to $2 \times 10^{5} \mathrm{~V} / \mathrm{cm}$ when the gap of the buffer layer increases from $1.4 \mathrm{eV}$ to $1.55 \mathrm{eV}$. However, the density of photogenerated holes traped at $i / p$ interface decreases from $2 \times 10^{19} \mathrm{~cm}^{-1}$ to $5 \times 10^{18} \mathrm{~cm}^{-3}$, when the buffer layer band gap increases from $1.40 \mathrm{eV}$ to $1.55 \mathrm{eV}$. Consequently, the value of efficiency increases from $10.89 \%$ to $11.33 \%$.

\section{ACKNOWLEDGEMENTS}

The authors are grateful to Professor S. Fonash from the Pennsylvania State University for providing the AMPS-1D program used in this work. 


\section{REFERENCES}

1. H. Tan, P. Babal, M. Zeman, Arno H.M. Smets, Sol. Energ. Mater. Sol. C. 132, 597 (2015).

2. A.V. Shah, J. Meier, E. Vallat-Sauvain, C. Droz, U. Kroll, N. Wyrsch, J. Guillet, U. Graf, Thin Solid Films 403-404, 179 (2002).

3. D.L. Staebler, C.R. Woronski, Appl. Phys. Lett. 31, 292 (1977).

4. A. Klaver, R.A.C.M.M. van Swaaij, Sol. Energ. Mater. Sol. C. 92, 50 (2008)

5. B. Yan, J. Yang, S. Guha, J. Vac. Sci. Technol. A $\mathbf{3 0}$, 04D108 (2008).

6. B. Yan, G. Yue, J. Yang, S. Guha, Sol. Energ. Mater. Sol. C. 111, 90 (2013).

7. J.J.H. Strengers, F.A. Rubinelli, J.K. Rath, R.E.I. Schropp, Thin Solid Films 501, 291 (2006).

8. J. Meier, J. Spitznagel, U. Kroll, C. Bucher, S. Faÿ, T. Moriarty, A. Shah, Thin Solid Films 451-452, 518 (2004).

9. P. Buehlmann, J. Bailat, D. Dominé, A. Billet, F. Meillaud, A. Feltrin, C. Ballif, Appl. Phys. Lett. 91, 143505 (2007).
10. F. Finger, Y. Mai, S. Klein, R. Carius, Thin Solid Films 516, 728 (2008).

11. Y. Mai, S. Klein, R. Carius, H. Stiebig, X. Geng, F. Finger, Appl. Phys. Lett. 87, 073503 (2005).

12. P.J. McElheny, J.K. Arch, H.-S. Lin, S.J. Fonash, J. Appl. Phys. 64, 1254 (1988).

13. S. Fonash, J. Arch, J. Hou, W. Howland, P. Mcelheny, A. Moquin, M. Rogosky, T. Tran, H. Zhu, F. Rubinelli, A Manual for AMPS-1D for windows 95/NT a OneDimensional Device Simulation Program for the Analysis of Microelectronic and Photonic Structures (The Pennsylvania State University: 1997).

14. A. Belfar, B. Amiri, H. Ait Kaci, J. Nano- Electron. Phys. 7 No 2, 02007 (2015).

15. A. Belfar, H. Ait Kaci, Thin Solid Films 525, 167 (2012).

16. A. Belfar, Sol. Energ. 114, 408 (2015).

17. K.S. Lim, M. Konagai, K. Takahashi, J. Appl. Phys. 56, 538 (1984).

18. S. Liu, X. Zeng, W. Peng, H. Xiao, W. Yao, X. Xie, C. Wang, Z. Wang, J. Non-Cryst. Solids 357, 121 (2011). 